\title{
Mechanical Safety Study and Antibiotic-loaded Polymethylmethacrylate Spacers Threshold, Manufactured Intraoperatively, in Orthopaedic Surgery
}

\author{
ADRIAN CURSARU ${ }^{1,2}$, BOGDAN CRETU ${ }^{1,2 *}$, BOGDAN SERBAN ${ }^{1,2}$, \\ ALEXANDRU GEORGE LUPU ${ }^{1,2}$, GEORGIAN IACOBESCU ${ }^{1,2}$, MIHNEA POPA ${ }^{1,2}$, \\ RALUCA CURSARU ${ }^{3}$, CATALIN CIRSTOIU ${ }^{1,2}$ \\ ${ }^{1}$ University Emergency Hospital Bucharest, Orthopaedic Department, 169 Splaiul Independentei Str., 050098, Bucharest, \\ Romania \\ 2"Carol Davila" University of Medicine and Pharmacy Bucharest, Faculty of Medicine, Orthopaedic Department, 8 Eroii \\ Sanitari Blvd., 050474, Bucharest, Romania \\ 3"N. C. Paulescu" National Institute of Diabetes, Nutrition and Metabolic Diseases, 5-7 Ion Movila Str., 020475, Bucharest, \\ Romania
}

Abstract: The study performed the biomechanical testing of polymethylmethacrylate (PMMA) specimens with unreinforced progressive antibiotic loading, compared to samples reinforced with Kirschner wires, by subjecting these specimens to mechanical compression forces. A difference was observed in the yield of the reinforced specimens with Kirschner wires, in which an antibiotic concentration that exceeded the usual amount was used. In this antibiotic combination of vancomycin powder and liquid gentamicin, the spacer seemed to have a superior structure compared to using only the antibiotic in liquid form. These results are superior to the usually loaded specimens (not exceeding the threshold of $4 \mathrm{~g}$ of antibiotic per $40 \mathrm{~g}$ of cement), the maximum force recorded being of $20.98 \mathrm{kN}$ and the minimum of 11.54 $k N$. The reinforced specimens indicated higher values of force, registering differences that varied between $10 \mathrm{kN}$ and approximately $19 \mathrm{kN}$, thus considering that through the reinforcement with Kirschner wires, the biomechanical qualities of the cement spacers considerably improved.

Keywords: polymethylmethacrylate spacers, reinforcement, antibiotic loading

\section{Introduction}

In cases of positive cultures, antibiotic-loaded polymethylmethacrylate specimens in accordance with the antibiogram is the key to treating the infection of patients with septic knee prosthesis [1].

According to literature, the antibiotic loading is performed with 2 to maximum $4 \mathrm{~g}$ of polymethylmethacrylate (standard value of a cement envelope) for mechanical safety reasons that interest the mechanical resistance of the polymethylmethacrylate spacer, however, no case with side effect at a higher loading has been demonstrated in literature [2,3].

In order to achieve a higher rate of success in treating PJI (periprosthetic joint infection), we conducted a study that analyzed the antibiotic loading with a larger amount of PMMA (but within limits of mechanical safety) in collaboration with the "Faculty of Mechanical Engineering and Mechatronics" at the Polytechnic University of Bucharest.

In medical application, Polymethylmethacrylate (PMMA) is an acrylic polymer formed by mixing two sterile components: a liquid methacrylate (MMA) monomer and a powered MMA-styrene copolymer [1]. Hardened PMMA is formed after mixing the two components, the liquid monomer polymerizing around the prepolymerized powder particles. Heat is generated during the process due to the exothermic reaction [4].

Along with the presence of various additives, PMMA offers the mixture a set of physical and chemical properties [5].

\footnotetext{
*email: jfrbogdan@yahoo.com
} 
Considering that the Kirschner (K.) wired spacers lead to an increase of their mechanical resistance, in this study, we performed the biomechanical testing of PMMA specimens with unreinforced progressive antibiotic loading, compared to samples reinforced with $\mathrm{K}$. wires, by subjecting these specimens to mechanical compression forces [6].

The aim of this study was to assess the threshold of mechanical safety of PMMA spacers manufactured after progressive loading with various antibiotics, in order to establish the maximum dose of antibiotic loading within mechanical safety conditions that can be used in current surgical practice.

\section{Materials and methods}

In order to be subjected to mechanical forces, we created 14 specimens (PMMA samples), each specimen being made of $40 \mathrm{~g}$ of cement, which were progressively loaded with antibiotic.

The cement used was of dual viscosity type, meaning that it had an increased resistance to other types of PMMA spacers [7].

The following antibiotics were used for loading: vancomycin powder and gentamicin vials.

Vancomycin (Fresenius Kabi), gentamicin (Krka d.d Novo mesto) and the cement (AMINO FIX 1, Groupe Lepine) were obtained from own funds.

7 sets of PMMA spacers (14 specimens) were made and were progressively loaded, each set containing one unreinforced specimen and one reinforced with Kirschner wires (Table 1).

Table 1. Specimens from the study group

\begin{tabular}{|c|c|}
\hline $\begin{array}{l}\text { STUDY GROUP } 1 \\
\end{array}$ & STUDY GROUP 4 \\
\hline $\begin{array}{l}\text { This study group represents the control group, being cement without } \\
\text { antibiotic loading }\end{array}$ & Vancomycin loading within limits of mechanical safety \\
\hline SG1A - without reinforcement & SG4A - without reinforcement \\
\hline $\begin{array}{c}\text { SG1B - with reinforcement of K wires } \\
\text { Amount of antibiotic }-0 \mathrm{~g}-\text { CONTROL GROUP }\end{array}$ & SG4B - with reinforcement of K wires \\
\hline STUDY GROUP 2.0 & Amount of antibiotic $-2 \mathrm{~g}$ of vancomycin \\
\hline Gentamicin loading within limits of mechanical safety & STUDY GROUP 5 \\
\hline SG01 - without reinforcement & $\begin{array}{l}\text { Vancomycin and gentamicin loading while overcoming the } \\
\text { threshold of mechanical safety }\end{array}$ \\
\hline SG02 - with reinforcement of K wires & SG5A - without reinforcement \\
\hline Amount of antibiotic $-2 \mathrm{~mL}$ of gentamicin & SG5B - with reinforcement of K wires \\
\hline STUDY GROUP 2 & Amount of antibiotic $-5 \mathrm{~g}$ of vancomycin $+5 \mathrm{~mL}$ of gentamicin \\
\hline Gentamicin loading & $\begin{array}{l}\text { STUDY GROUP } 6 \\
\end{array}$ \\
\hline SG2A - without reinforcement & Prefabricated gentamicin loading \\
\hline SG2B - with reinforcement of K wires & SG6A - without reinforcement \\
\hline Amount of antibiotic $-4 \mathrm{~mL}$ of gentamicin & SG6B - with reinforcement of K wires \\
\hline STUDY GROUP 3 & Amount of antibiotic $-0.5 \mathrm{~mL}$ of gentamicin \\
\hline \multicolumn{2}{|l|}{ Gentamicin loading } \\
\hline \multicolumn{2}{|l|}{ SG3A - without reinforcement } \\
\hline SG3B - with reinforcement of $\mathrm{K}$ wires & \\
\hline Amount of antibiotic $-8 \mathrm{~mL}$ of gentamicin & \\
\hline
\end{tabular}

The maximum amount of antibiotic used to load the spacers was $8 \mathrm{~mL}$ of gentamicin alone and $6 \mathrm{ml}$ of gentamicin combined with $5 \mathrm{~g}$ of vancomycin per $40 \mathrm{~g}$ of cement.

The reinforcement of the PMMA spacers was made with Kirschner wires.

Two specimens were made for each sample, with and without reinforcement.

4 Kirschner wires of $3.5 \mathrm{~cm}$ were inserted when loading each specimen, being weighed in order to calculate the weight-size gradient difference after subjecting them to compression forces.

For a correct interpretation of the results of the specimens' forces during their subjection to compression stress, we decided to correct the material by sectioning each sample. Thus, a uniform support surface resulted, avoiding the possible errors caused by an incorrect support and influenced by the uneven forces.

Two flat surfaces prepared for a correct compression resulted after cutting.

Measurement and weighing of each test specimen were performed after this process. 
Elastic to plastic transition represents the value of the force at which the transition from a linearelastic field to a plastic field occurred, with the residual deformation determined by $1^{\text {st }}$ order derivative of the force-shortage curve to reduce the errors due to the operator (Figure 1). Dividing this value by the transverse surface, we could determine the compression resistance of the specimen.

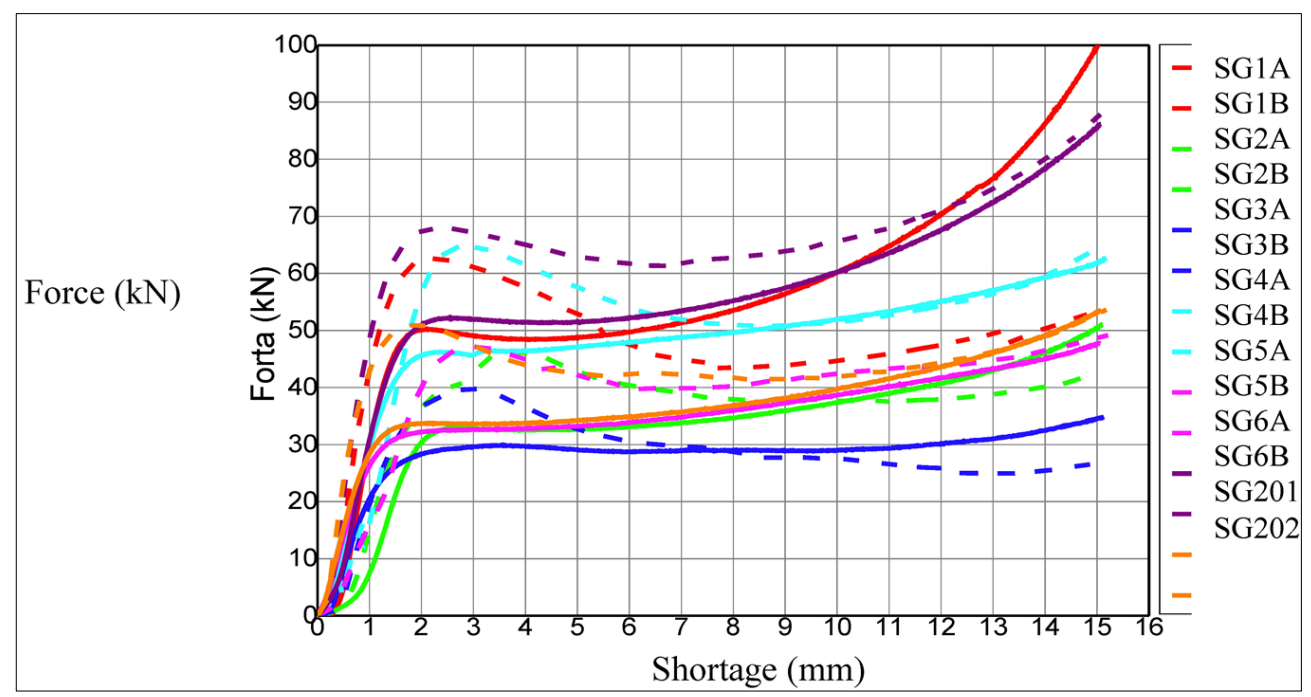

Figure 1. Stress deformation curve of the studied group

\subsection{Subjection to compression forces}

A Walter-Bai Ag model CH-8224 (Figure 2) device was used for subjection to compressive forces, which accurately automatically recorded the yielding of materials and the change of shape of materials with elastic structure (like in the case of methacrylate used in this study) [8].

This testing system has the ability to accurately quantify uniaxial, multiaxial and torsional stress forces.

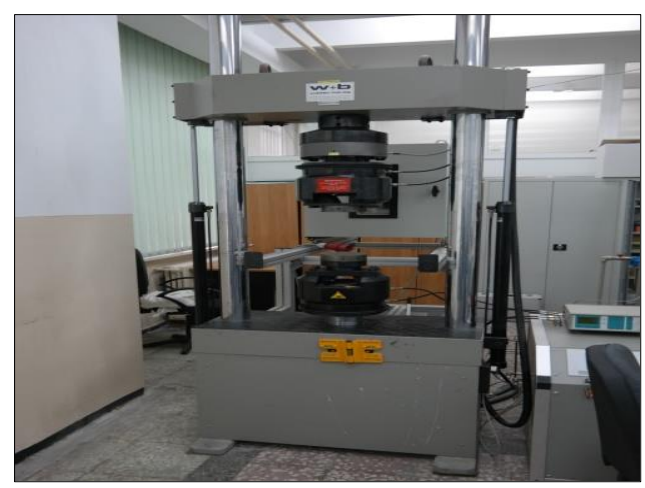

Figure 2. Walter-Bai Ag stress device

Shape changes were recorded (being considered the initial yield point of the material) for each mechanically tested specimen, all data being recorded as graphs of material elasticity.

\section{Results and discussions}

\subsection{Processing and interpreting values}

The line indicated only elastic deformations, followed by a significant plastic flow. The subsequent increase of the force was explained by the increase of the surface.

1. The $1^{\text {st }}$ derivative of the curve was made

2. The inflection point, where the curve changed its appearance, was determined 


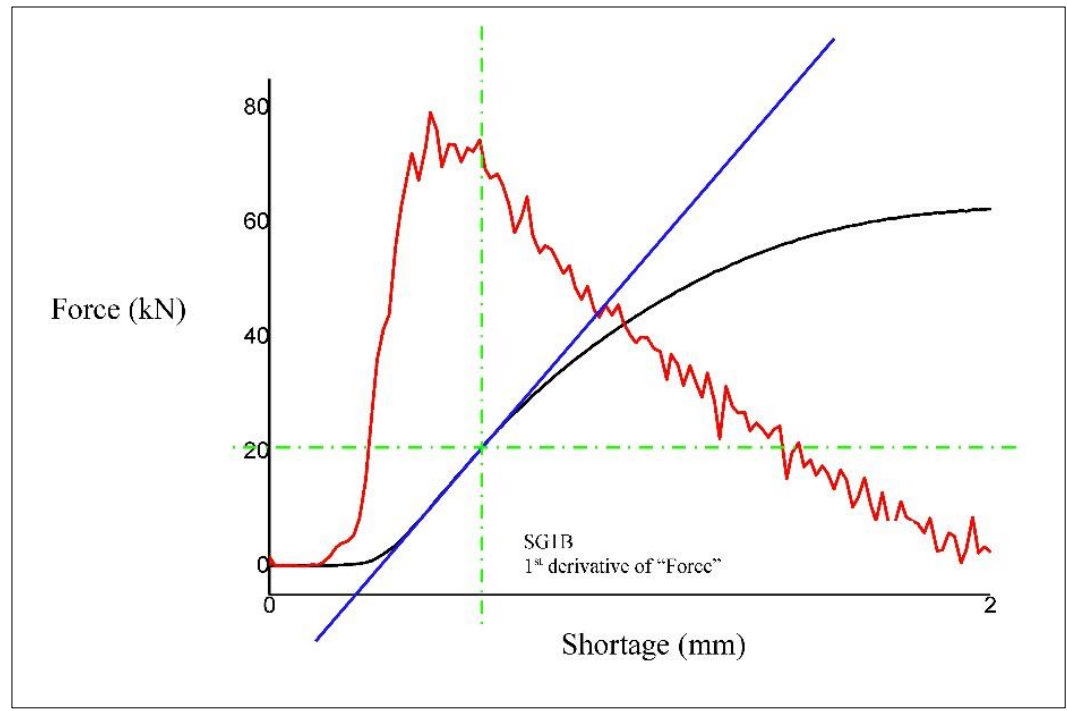

Figure 3. Determination module

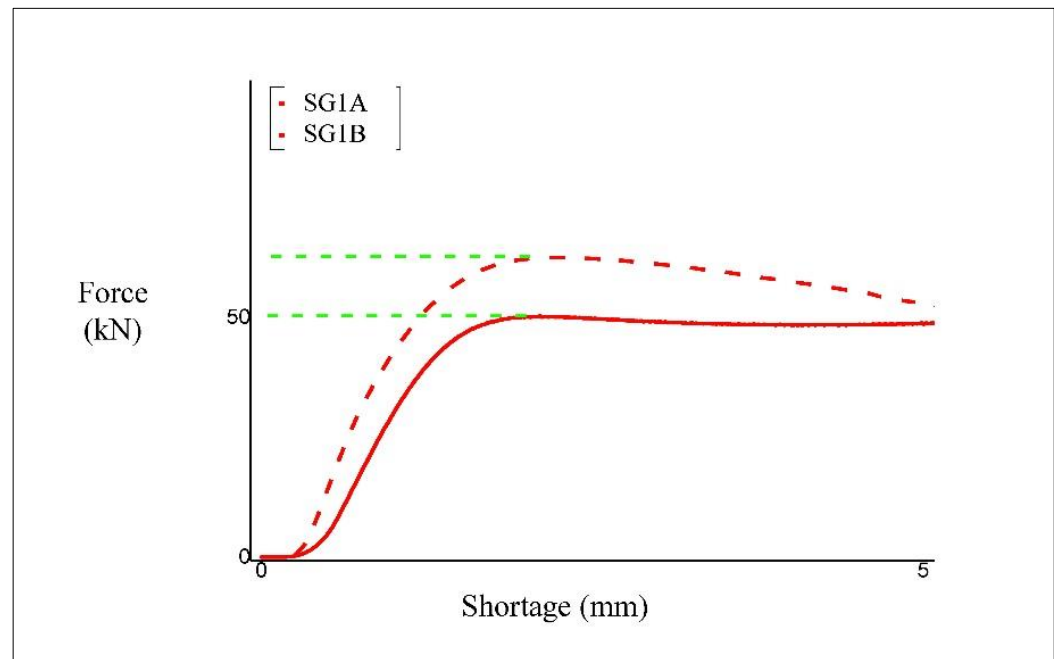

Figure 4. Maximum force value in the deformation area

According to the method of determination shown in the figure above, we could practically associate this value with the maximum force that the specimen can take until it yields.

We were able to determine the compression resistance of the specimen by dividing this value to the transverse surface.

A difference was observed in the yield of the reinforced specimens with Kirschner wires, in which an antibiotic concentration that exceeded the usual amount was used.

The spacer appeared to have a superior structure compared to using the antibiotic only in liquid form, while in this antibiotic combination of vancomycin powder and liquid gentamicin.

These results are superior to the usually loaded specimens (not exceeding the threshold of $4 \mathrm{~g}$ of antibiotic per $40 \mathrm{~g}$ of cement).

The yield threshold indicated by the change in the stress shape of the specimens from plastic to elastic is not a threshold that can be reached in joint biomechanics. In addition, we concluded that this antibiotic loading, which exceeded the usual threshold, was not accompanied by a possible mechanical complication of the joint spacer [9]. 


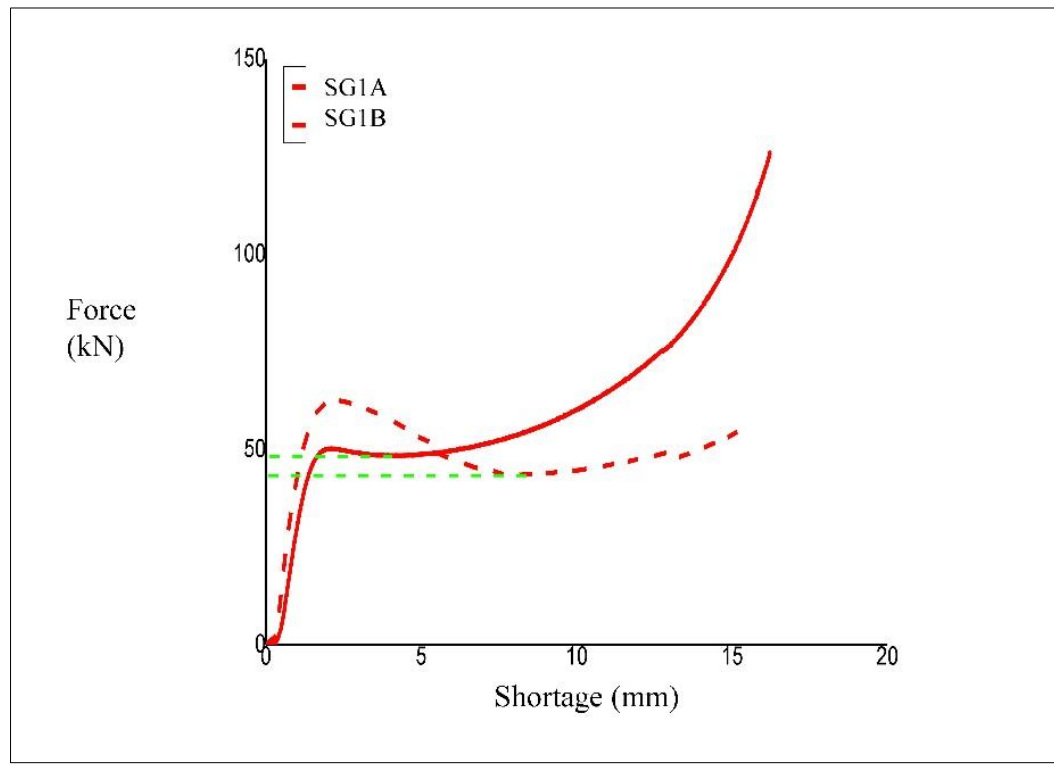

Figure 5. Bearing force value

Basically, after leaving the bearing, we considered that the specimen would have yielded, its integrity being strongly affected.
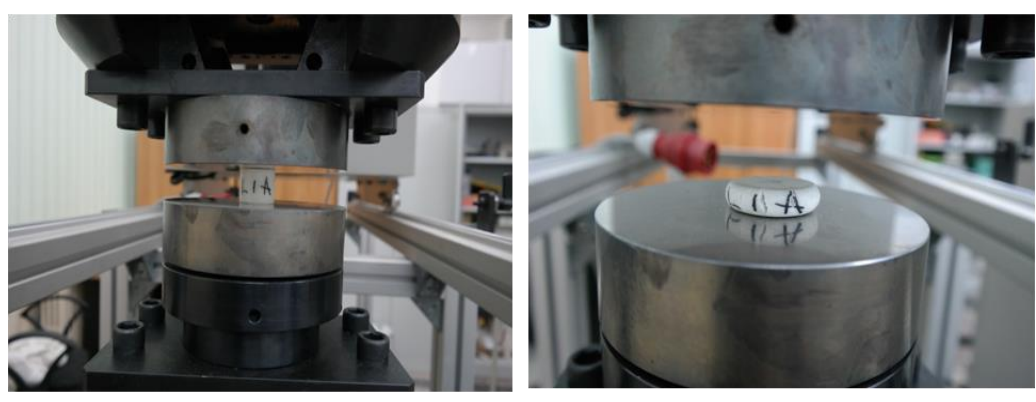

Figure 6. Before and after mechanical stress of specimens

Table 2. Value of specimens' difference to mechanical stress

\begin{tabular}{|c|c|c|c|c|c|}
\hline Sample & $\begin{array}{c}\text { Antibiotic addition } \\
{[\mathrm{g}]}\end{array}$ & $\begin{array}{c}\text { Elasticity limit } \\
{[\mathrm{km}]}\end{array}$ & $\begin{array}{c}\text { Maximum force in } \\
\text { the deformation } \\
\text { region }[\mathrm{km}]\end{array}$ & Bearing force $[\mathrm{km}]$ & $\begin{array}{c}\text { Maximum-bearing } \\
{[\mathrm{km}]}\end{array}$ \\
\hline SG1A & 0 & 17.5536 & 50.3118 & 48.4218 & 1.89 \\
\hline SG1B & 0 & 20.1696 & 62.6268 & 43.569 & 19.0578 \\
\hline SG2A & 4 & 17.3094 & 32.9793 & 32.4912 & 0.4881 \\
\hline SG2B & 4 & 14.8419 & 46.4622 & 37.7001 & 8.7621 \\
\hline SG3A & 8 & 12.4038 & 29.9673 & 28.9218 & 1.0455 \\
\hline SG3B & 8 & 16.5507 & 39.8544 & 27.5427 & 12.3117 \\
\hline SG4A & 2 & 18.2364 & 46.2378 & 46.3137 & -0.0759 \\
\hline SG4B & 2 & 16.3692 & 65.0055 & 50.7111 & 14.2944 \\
\hline SG5A & 5 & 11.5398 & 32.5638 & 32.7585 & -0.1947 \\
\hline SG5B & 5 & 13.3671 & 47.2044 & 39.7719 & 7.4325 \\
\hline SG6A & 0.5 & 19.9389 & 52.3542 & 51.3018 & 1.0524 \\
\hline SG6B & 0.5 & 20.9811 & 68.0964 & 61.3104 & 6.786 \\
\hline SG201 & 2 & 14.037 & 33.7779 & 33.5898 & 0.1881 \\
\hline SG202 & 2 & 20.2719 & 50.9418 & 42.0447 & 8.8971 \\
\hline SG1A-SG1B & -- & -2.616 & -12.315 & 4.8528 & -- \\
\hline SG2A-SG2B & -- & 2.4675 & -13.4829 & -5.2089 & -- \\
\hline SG3A-SG3B & -- & -9.1677 & -9.8871 & 1.3791 & -- \\
\hline SG4A-SG4B & -- & 1.8672 & -18.7677 & -4.3974 & -- \\
\hline SG5A-SG5B & -- & -1.8273 & -14.6406 & -7.0134 & -- \\
\hline SG6A-SG6B & -- & -1.0422 & -15.7422 & -10.0086 & -8.4549 \\
\hline SG201-SG202 & -- & -6.2349 & -17.1639 & & - \\
\hline Mater. Plast., 57 (4), 2020 & & 321 & https://doi.org/10.37358/MP.20.4.5431 \\
\hline
\end{tabular}


The elastic to plastic transition (indicated by the specimen's shape change in stress) was considered the yielding point of the material.

Thus, there were variations, the maximum force recorded being of $20.98 \mathrm{kN}$ and the minimum of $11.54 \mathrm{kN}$, resulting an interval of $9.44 \mathrm{kN}$.

From the compared sets of specimens, the reinforced ones showed a higher force value.

The differences highlighted in the table above are of maximum $19 \mathrm{kN}$.

Transition from elastic to plastic (indicated by the changing of the specimen on stress) was considered the bending point of the material. The maximum strength force was $20.98 \mathrm{kN}$ and minimum 11.54 kN. Differences observed were 6 kN (Figure 7).

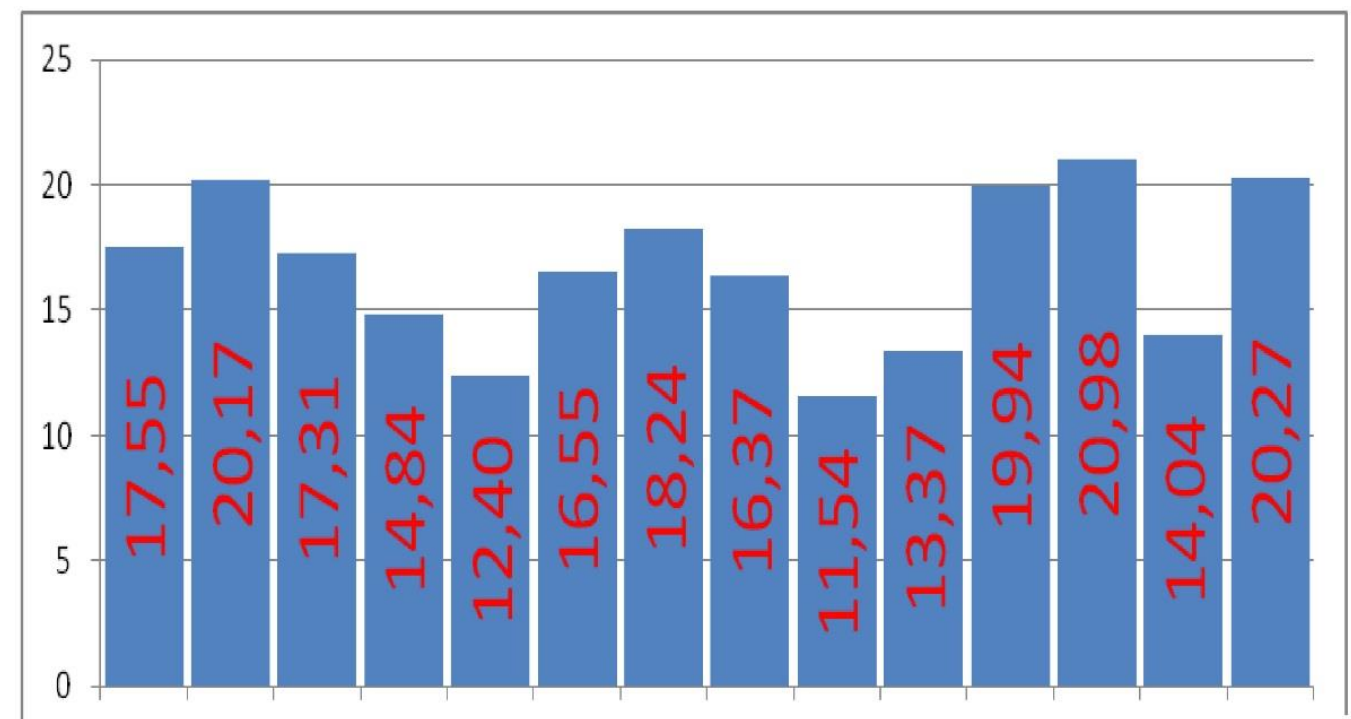

SG1A SG1B SG2A SG2B SG3A SG3B SG4A SG4B SG5A SG5B SG6A SG6B SG201 SG202

Figure 7. Elastic-plastic transition

Reinforced specimens show higher values when it comes to bending points because of the metallic wires. The differences varied between $10 \mathrm{kN}$ and $19 \mathrm{kN}$ (Figure 8).

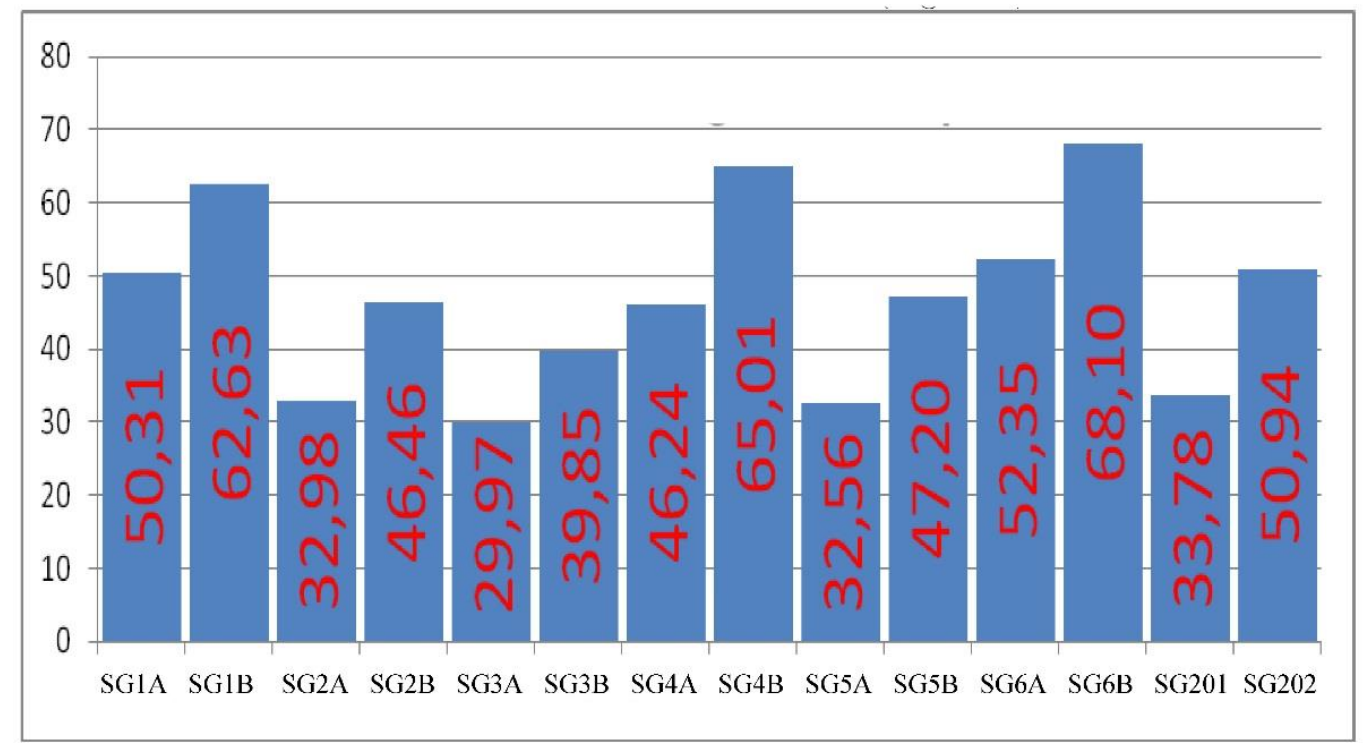

Figure 8. Maximum onset force 
The maximum bearing force was registered on SG6B $(61.31 \mathrm{kN})$, specimen composed of prefabricated gentamicin cement with reinforced K wires (Figure 9).

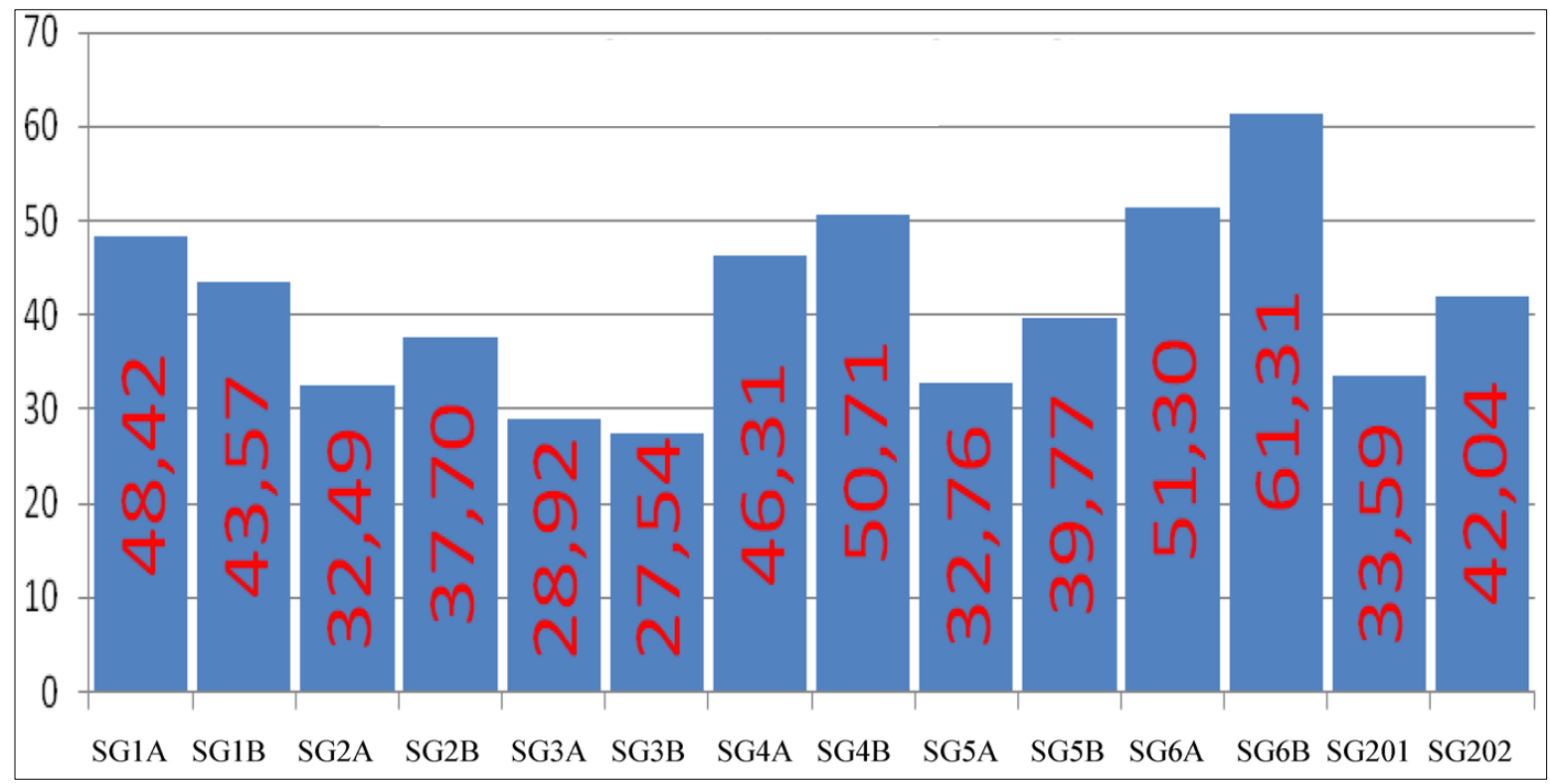

Figure 9. Maximum bearing force

According to literature, reinforced specimens showed higher force values, the influence of metal reinforcements being observed [9]. The differences varied between $10 \mathrm{kN}$ and approximately $19 \mathrm{kN}$. Unreinforced spacers have a high rate of mechanical complications, in study performed by Yang et all the rate was $9.7 \%$ and led to important changes in the patient overall outcome [10].

\section{Conclusions}

Comparing the maximum force in the deformation region of the control group SG1A (the unreinforced specimen without antibiotic loading) which was $50.3 \mathrm{kN}$, to the reinforced specimen with Kirschner wires and loading of $5 \mathrm{~g}$ of antibiotic (of which $3 \mathrm{~g}$ of vancomycin and $2 \mathrm{~mL}$ of gentamicin), $\mathrm{SG} 5 \mathrm{~B}$, which was $47.2 \mathrm{kN}$, a small difference of $3.1 \mathrm{kN}$ was registered. Hence, it did not represent a significant difference that could lead to a degradation of joint dynamics.

The reinforced specimens showed higher force values, registering differences that varied between 10 $\mathrm{kN}$ and approximately $19 \mathrm{kN}$, thus considering that this reinforcement with $\mathrm{K}$. wires considerably improved the biomechanical qualities of the cement spacers intraoperatively.

The bending threshold underlined by the specimens' shape change in stress, from plastic to elastic, does not represent a threshold that can be reached in joint biomechanics. Thus, we can conclude that this antibiotic loading, which exceeds the usual threshold, is not accompanied by a possible mechanical complication of the joint spacer.

\section{References}

1. MATTHEW C. SWEARINGEN, JEFFREY F. GRANGER, ANNE SULLIVAN, PAUL STOODLEY, Elution of antibiotics from poly (methyl methacrylate) bone cement after extended implantation does not necessarily clear the infection despite susceptibility of the clinical isolates, Pathogens and Disease, Volume 74, Issue 1, February 2016, ftv103, https://doi.org/10.1093/femspd/ftv103

2. CHUANG, Y., JIN, W., ZHIFEI, Y., QIAOJIE, W., XIANLONG, Z., YAO, J., HAO, S., A sophisticated antibiotic-loading protocol in articulating cement spacers for the treatment of prosthetic joint infection, A retrospective cohort study, Bone \& Joint Research, 8(11), 2019.

3.IARIKOV, D., DEMIAN, H., RUBIN, D., ALEXANDER, J., NAMBIAR, S., Choice and Doses of Antibacterial Agents for Cement Spacers in Treatment of Prosthetic Joint Infections: Review of Published Studies, Clinical Infectious Diseases, 55(11):1, December 2012. 
4.BOWEN, B., Orthopedic Surgery, Alexander's Care of the Patient in Surgery, In: Rothrock JC, editor., 14th ed., Mosby, St. Louis, MO, 2011, 741-742.

5.ASCHERL, R., Science of Bone Cement. Ortho Supersite, Available at:

http://www.orthosupersite.com/view.asp?rID=3971.

6.KAKU N, TABATA T, TSUMURA H. Mechanical evaluation of hip cement spacer reinforcement with stainless steel Kirschner wires, titanium and carbon rods, and stainless-steel mesh. Eur J Orthop Surg Traumatol. 2015;25(3):489-496. doi:10.1007/s00590-014-1567-0

7.VAISHYA R, CHAUHAN M, VAISH A. Bone cement. J Clin Orthop Trauma. 2013;4(4):157-163. doi:10.1016/j.jcot.2013.11.005

8.BOUZAKIS, K.D., MICHAILIDIS, N., MESOMERIS, G., ANAGNOSTIDIS, K., KIRKOS, J., KAPETANOS, G., Investigation of mechanical properties of antibiotics-loaded acrylic bone cement. Proceedings of the 3rd International Conference on Manufacturing Engineering (ICMEN), 1-3 October 2008, Khalkidhiki, Greece. Available from: https://www.researchgate.net/ publication/237669337.

9.KENT, M., RACHHA, R., SOOD, M., A technique for the fabrication of a reinforced moulded articulating cement spacer in two stage revision total hip arthroplasty, Int Orthop, 34(7), 2010 Oct, 949-953.

10.YANG FS, LU YD, WU CT, BLEVINS K, LEE MS, KUO FC. Mechanical failure of articulating polymethylmethacrylate (PMMA) spacers in two-stage revision hip arthroplasty: the risk factors and the impact on interim function. BMC Musculoskelet Disord. 2019;20(1):372. Published 2019 Aug 14. doi:10.1186/s12891019-2759-x

$\overline{\text { Manuscript received: } 19.08 .2020}$ 